Reprinted from:

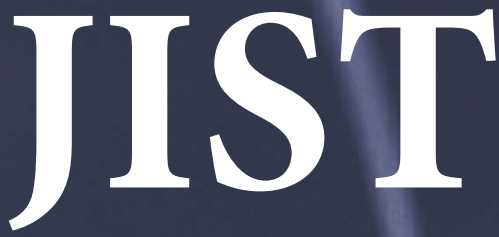

Vol. 53, No. 2 March/April 2009

Journal of

Imaging Science

and Technology

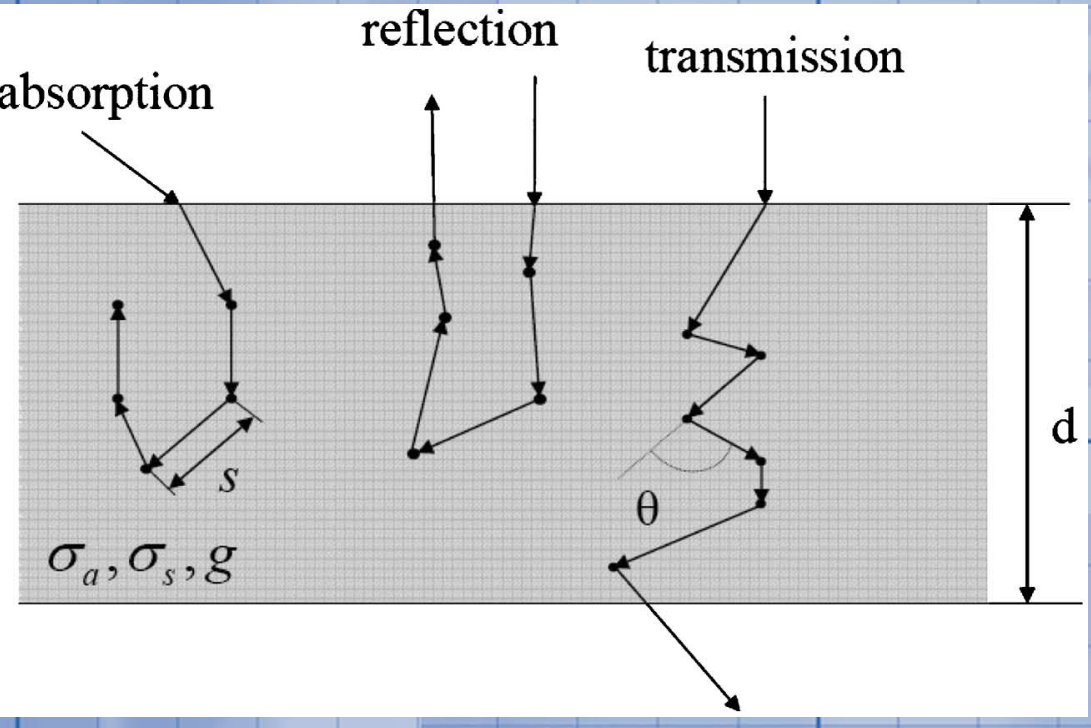

Society for Imaging Science and Technology 


\title{
A Highly Stable Charge-Control Agent Based on an Al-Complex with Salicylic Acid Derivatives Used for Full Color Toners
}

\author{
Yuya Kamei and Jin Mizuguchi ${ }^{-}$ \\ Graduate School of Engineering, Yokohama National University, 79-5 Tokiwadai, Hodogaya-ku, 240-8501 \\ Yokohama, Japan \\ E-mail: mizu-j@ynu.ac.jp \\ Osamu Yamate \\ Orient Chemical Industries, LTD., 541-0057 Osaka, Japan
}

\begin{abstract}
An Al-complex with salicylic acid derivatives as ligands (commercial product E-88 from Orient Chemical Industries) is a typical commercial charge-control agent (CCA). At present, E-88 is widely used for full color toners, since it is colorless. However, E-88 possesses a relatively low and broad decomposition range between 130 and $170^{\circ} \mathrm{C}$. For this reason, an attempt has been made in the present study to improve the thermal stability by investigating a new polymorph that possesses a higher thermal stability. Trial was then made to grow crystals by recrystallization from solution in various solvents. Among these, dimethylsulfoxide gave a hexanuclear Alcomplex (molecular weight: 3310) that exhibits an extraordinarily high decomposition temperature of $270^{\circ} \mathrm{C}$. In addition, this compound is found to exhibit excellent charge-control performance. Furthermore, the temperature dependence of the electrical conductivity of E-88 has also been studied in connection with our previously proposed charge-control mechanism of CCAs. () 2009 Society for Imaging Science and Technology.
\end{abstract}

[DOI: 10.2352/J.ImagingSci.Technol.2009.53.2.020503]

\section{INTRODUCTION}

The title compound (Al-complex with salicylic acid derivatives as ligands: E- 88 from Orient Chemical Industries, LTD) is a charge-control agent (CCA) of the negative type that creates a desired charge level and polarity when used in a toner. E-88 is appropriate for full color toners (yellow, magenta, and cyan) because it is colorless. A further advantage of $\mathrm{E}-88$ is the use of environmentally friendly $\mathrm{Al}$ as the central metal. Figure 1 shows the structure according to CAS No. 41699-28-9, showing a six-coordinate Al-complex (molecular weight: 774.9) that includes three molecules of 3,5-t-butyl salicylic acid (TBS: Figure 2). Each TBS serves as a bidentate ligand $(\mathrm{Al} / \mathrm{TBS}=1 / 3)$ : the $\mathrm{O}$ atom of the carboxyl group (No. 2 position in Fig. 2) and the $\mathrm{O}$ atom of the hydroxyl group (No. 3 position in Fig. 2); whereas No. 1 and No. 2 positions are usually used for bidentate ligands of the carboxyl group. However, E-88 possesses a relatively low and

\section{IS\&T Member.}

Received Aug. 23, 2008; accepted for publication Jan. 3, 2009; published online Mar. 6, 2009.

$1062-3701 / 2009 / 53(2) / 020503 / 6 / \$ 20.00$. very broad decomposition range between 130 and $170^{\circ} \mathrm{C}$. Obviously, a higher temperature stability is necessary for E- 88 , because pulverized toners are usually manufactured by kneading CCA, at $130-180^{\circ} \mathrm{C}$, with various toner components such as polymer resin, pigments, wax, etc. For this reason, an attempt has been made primarily to improve the thermal stability by investigating a new polymorph that possesses a higher thermal stability. Trial was then made to grow single crystals by recrystallization from solution in various solvents. Among these, single crystals were isolated from a dimethylsulfoxide (DMSO) solution. Structure analysis of this compound revealed the formation of a hexanuclear Alcomplex that exhibits an extraordinarily high decomposition temperature of $270^{\circ} \mathrm{C}$.

Second, we have investigated the temperature dependence of the electrical conductivity of E-88 in an attempt to provide additional evidence for our charge-control mechanism of charge-control agents (CCAs). ${ }^{1}$ Our proposed model assumes an appreciable temperature increase at the "toner/carrier" interface due to the triboelectrification. A trace of CCA, which exists at the interface, can also be heated above $100^{\circ} \mathrm{C}$ to become electrically conductive, since CCA is an organic semiconductor and the electrical conduc-

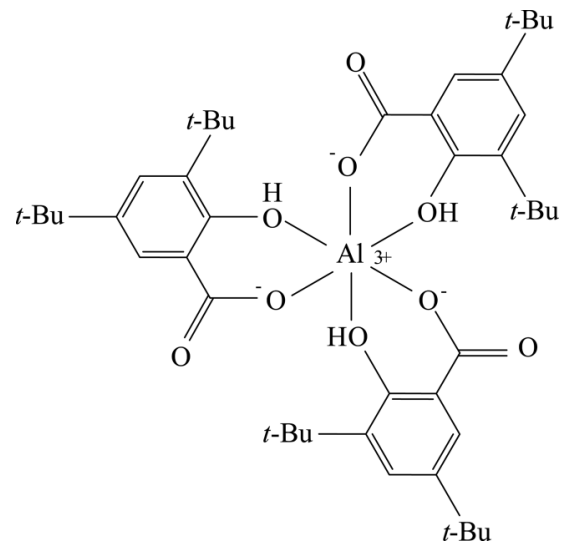

Figure 1. Molecular conformation of E-88 according to CAS No. $41699-28-9$. 


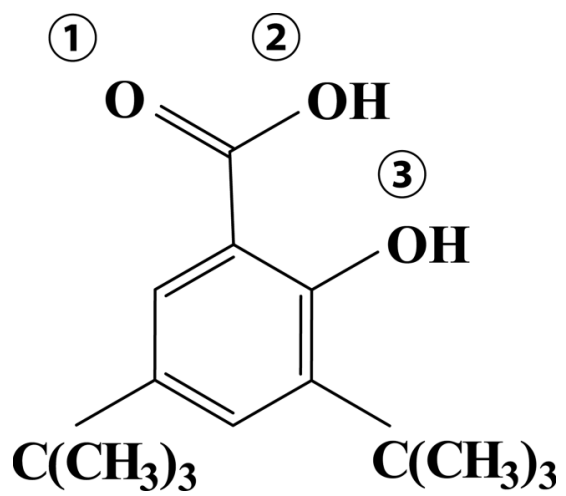

Figure 2. Molecular structure of the 3,5-t-butyl-salicylic acid (TBS). The numbers 1, 2, and 3 designate the ligand positions.

tivity of semiconductors is known to increase exponentially with temperature. ${ }^{2}$ This forms a conductive channel through which the carrier flow occurs efficiently to charge the toner. The increase in electrical conductivity with increasing temperature facilitates the charge flow from toner to carrier, or vice versa. Therefore, the measurement of the temperature dependence provides important experimental evidence for our charge-control mechanism.

\section{EXPERIMENTAL}

\section{Crystal Growth of E-88 from Solution in Various}

\section{Solvents}

E-88 was obtained from Orient Chemical Industries, Ltd. An attempt was made to grow single crystals from solution in various solvents such as alcohols, ketones, ethers, and solvents used for organic pigments [dimethylsulfoxide (DMSO), dimethylacetamide (DMA), dimethylformamide (DMF), $N$-methylpyrrolidone (NMP), 1,4-dioxane, etc.]. Among these, colorless single crystals were isolated only from a DMSO solution in the form of blocks (size: $0.20 \times 0.10 \times 0.08 \mathrm{~mm}^{3}$ ). The single crystal was found to include solvent molecules according to thermal analysis.

\section{$X$-ray Structure Analysis}

Reflection data were collected on an R-Axis Rapid-F diffractometer from Rigaku using $\mathrm{Cu} K \alpha$ as the radiation source $(\lambda=1.5418 \AA)$ at $-180^{\circ} \mathrm{C}$. The structure was solved by direct methods (SHELXS97 ${ }^{3}$ ) and refinement was carried out by the full-matrix least-squares method of $F^{2}\left(\right.$ SHELXL97 $\left.^{4}\right)$.

\section{Sample Preparation for Electrical Measurements}

A thin layer of DMSO-solvated E-88 was directly prepared from a saturated DMSO solution by spin coating onto an indium tin oxide (ITO) interdigital electrode prepared in our laboratory as shown in Figure 3, in which the width of the electrodes and the spacing between the electrodes were both $100 \mu \mathrm{m}$. The sample was then dried in air at $165^{\circ} \mathrm{C}$ for $20 \mathrm{~min}$. The phase of the spin-coated layer was identified by $\mathrm{x}$-ray diffraction as the same phase as that of the single crystal grown from a DMSO solution.

\section{Measurements}

Thermogravimetric analysis (TGA) was made in air on powdered E-88, using a Rigaku Thermo Plus TG-8120 at a heat-

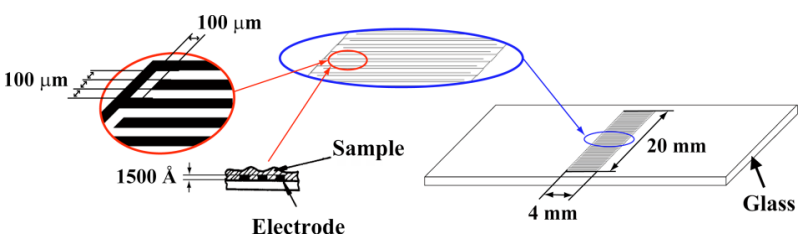

Figure 3. Interdigital electrode made of ITO. Both the width of the electrode and the spacing between the electrodes are $100 \mu \mathrm{m}$.

Table I. Crystallographic parameters for the hexanuclear Al-complex recrystallized from a DMSO solution.

\begin{tabular}{lc} 
Formula & $\mathrm{C}_{141} \mathrm{H}_{204} \mathrm{Al}_{6} \mathrm{O}_{33} \mathrm{~S}_{3} \cdot 8\left(\mathrm{C}_{2} \mathrm{H}_{6} \mathrm{OS}\right)$ \\
Molecular weight & 3310.24 \\
Crystal system & Monoclinic \\
Space group & $\mathrm{Cc}$ \\
$Z$ & 4 \\
$a(\AA)$ & $19.3525(4)$ \\
$b(\AA)$ & $35.4460(4)$ \\
$c(\AA)$ & $27.9608(7)$ \\
$\beta\left({ }^{\circ}\right)$ & $110.1240(7)$ \\
Density $\left(\mathrm{g} / \mathrm{cm}^{3}\right)$ & 1.224 \\
$R$ & 0.159 \\
\hline
\end{tabular}

ing rate of $10^{\circ} \mathrm{C} / \mathrm{min}$. Toners were prepared by kneading, at $130^{\circ} \mathrm{C}$ for several minutes, styrene-acrylic copolymer resin (100 parts: Almatex CPR600B $^{\mathrm{TM}}$ from Mitsui Chemicals), carbon black (6 parts: MA100 from Mitsubishi Chemical Corporation), wax (2 parts: VISCOL550P from Sanyo Kasei Co. Ltd.), and the hexanuclear Al-complex of E-88 recrystallized from a DMSO solution (1 part: Orient Chemical Industries, Ltd.).

Triboelectrification measurements were made on toners in accordance with the standard procedure specified by Imaging Society of Japan, using the blow-off equipment (TB-200: Toshiba Chemical).

The temperature dependence of the electrical conductivity was measured on the spin-coated sample described above in the temperature range between room temperature and $200^{\circ} \mathrm{C}$ by means of a 6514 Keithley electrometer with a heating rate of $3^{\circ} \mathrm{C} / \mathrm{min}$.

\section{RESULTS AND DISCUSSION Crystallographic Parameters and Molecular Conformation}

Table I details the crystallographic parameters for the DMSO-solvated crystal of E-88 (molecular weight: 3310) which contains eight free DMSO molecules. Figure 4(a) shows the conformation of the hexanuclear Al-complex and eight free DMSO molecules; whereas Fig. 4(b) is its schematic illustration without free DMSO molecules. Figure 5 is the extracted triangle composed of $\mathrm{Al} 1, \mathrm{Al} 3$, and $\mathrm{Al} 5$. The molecular environment around each Al-center is exactly the same. That is, the Al-complex includes six $\mathrm{O}$ atoms as 


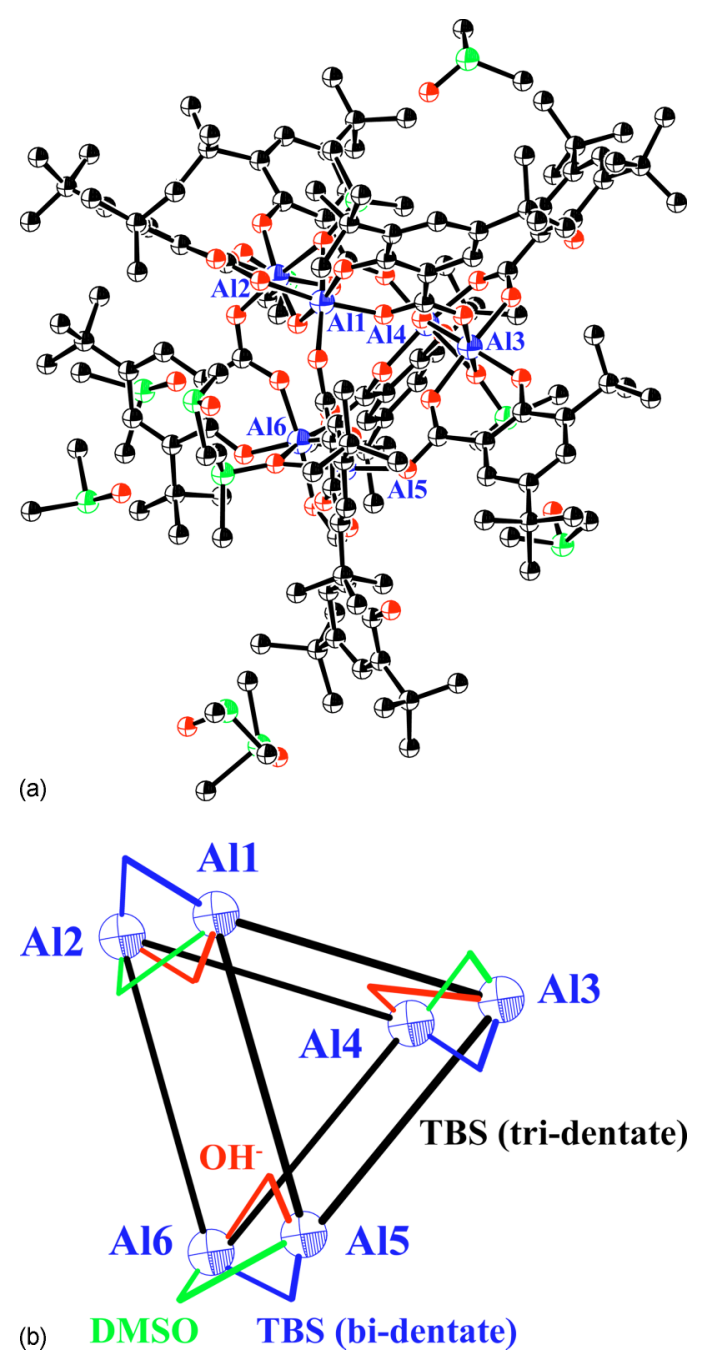

Figure 4. (a) Plot of DMSO-solvated E-88, where the $\mathrm{H}$ atoms are omitted for clarity. (b) Schematic illustration of the hexanuclear complex in the absence of free DMSO molecules.

ligands, of which four $\mathrm{O}$ atoms are from TBS, one $\mathrm{O}$ atom from DMSO, and another $\mathrm{O}$ atom from a hydroxyl anion.

The asymmetric unit is composed of six $\mathrm{Al}$ atoms, nine TBS molecules, eleven DMSOs, and three hydroxyl anions. Among nine TBSs, six TBS molecules serve as the tridentate ligands (positions of No. 1, No. 2, and No. 3 in Fig. 2), two of which are the $\mathrm{O}$ atoms of the carboxyl group (carboxylate: $\mathrm{C}=\mathrm{O}$ and $-\mathrm{O}^{-}$) and the third one is that of the hydroxyl group $\left(-\mathrm{O}^{-}\right)$. The remaining three TBSs work as the bidentate ligands $\left(\mathrm{C}=\mathrm{O}\right.$ and $-\mathrm{O}^{-}$in positions of No. 1 and No. 2 in Fig. 2). Likewise, eleven DMSO molecules include three DMSOs as the ligands and eight free DMSOs.

The hexanuclear Al-complex is pictured as composed of two triangles (i.e., trinuclear complex) as shown in Fig. 4(b), in which all apices are occupied by six $\mathrm{Al}$ atoms: (All, $\mathrm{Al} 3$, $\mathrm{Al} 5)$ and (Al2, Al4, Al6). In each triangle, $\mathrm{Al}$ atoms (for example, Al1/Al3 in Fig. 5) are bridged by tridentate TBSs. Similarly, bonding is made in Al3/Al5 and in Al5/All. In addition, two triangles are dimerized by three $\mathrm{O}$ atoms of each bidentate TBSs, three $\mathrm{O}$ atoms of each DMSO, and three $\mathrm{O}$ atoms of each hydroxyl anion, leading to the forma-

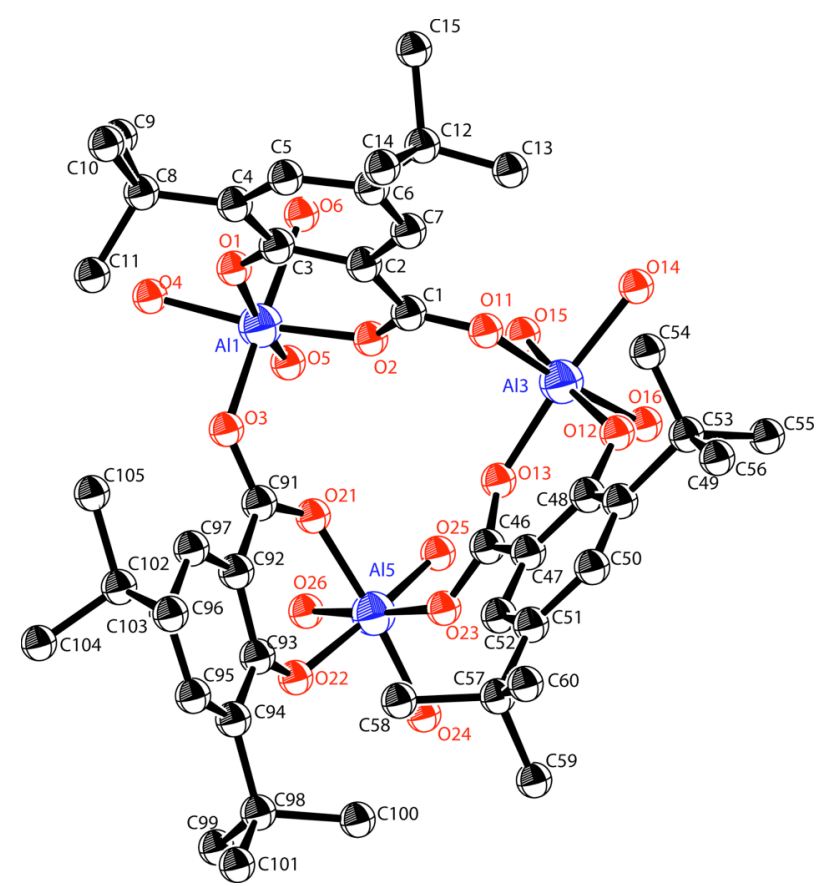

Figure 5. Illustration of one triangle (i.e., trinuclear Al-complexes) composed of three Al atoms (All, Al3, and Al5) and three tridentate TBS molecules.

tion of a hexanuclear complex. This gives a ratio of $\mathrm{Al} / \mathrm{TBS}=1 / 1.5$. That is, for example, Al1 in one triangle and $\mathrm{Al} 2$ in the other triangle are connected by one bidentate TBS $\left(\mathrm{C}=\mathrm{O}\right.$ and $-\mathrm{O}^{-}$in positions of No. 1 and No. 2 in Fig. 2), one DMSO, and one hydroxyl anion. Similarly, Al3/Al4 and Al5/Al6 are bridged together by TBS in the same way. One hydroxyl anion compensates one positive charge arising from the two $\mathrm{Al}$ atoms (for example, Al1/Al2) with four tridentate TBSs and one bidentate TBS. The presence of the hydroxyl anion (i.e., an alkali) may appear rather strange, but it is absolutely necessary from the viewpoint of the electrical neutrality of the molecule. The present six-nuclear complex constitutes a giant molecule (molecular weight: 3310 ) and its size is expected to greatly contribute to the thermal stability.

\section{Free DMSOs in the Bulk and Their Removal by Heat Treatment}

The hexanuclear complex as recrystallized is found to include eight free DMSOs as well as three DMSOs that served as ligands (i.e., coordinating solvent) to bridge two trinuclear complexes as shown in Fig. 4(a). The former DMSOs are thought to desorb at relatively low temperature, while the latter ones are assumed to remain more tenaciously in the crystal. Table II shows the result of the elementary analysis of the hexanuclear $\mathrm{Al}$ complex as recrystallized and heat-treated at $200^{\circ} \mathrm{C}$ for $1 \mathrm{~h}$. The analysis revealed clearly that eight free DMSOs are entirely removed by heat treatment, while the three bridging ligands of DMSO remain intact in the crystal.

\section{TGA Measurements}

Figure 6 shows the TGA curves for the hexanuclear complex with or without free DMSOs as well as for commercial E-88. 
Table II. Elementary analysis of the hexanuclear complex as recrystallized and heattreated at $200^{\circ} \mathrm{C}$ for $1 \mathrm{~h}$ expressed.

\begin{tabular}{ccccc}
\hline & $\mathrm{C}$ & $\mathrm{H}$ & $\mathrm{S}$ & $\mathrm{Al}$ \\
\hline Heat-treated hexanuclear Al-complex & 63.18 & 8.13 & 3.50 & 6.13 \\
$\begin{array}{c}\text { Theoretical value based on the composition: } \\
\mathrm{C}_{141} \mathrm{H}_{204} \mathrm{O}_{33} \mathrm{~S}_{3} \mathrm{Al}_{6}\end{array}$ & 63.07 & 7.66 & 3.58 & 6.03 \\
\hline
\end{tabular}

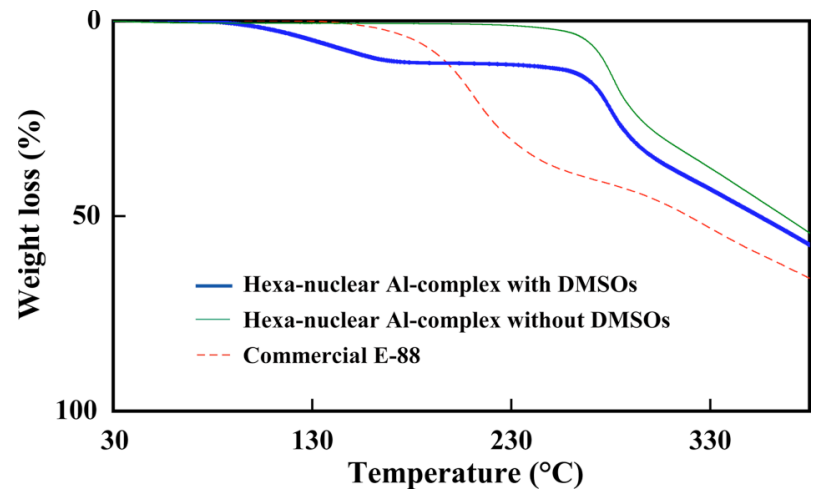

Figure 6. TGA curves for the hexanuclear complexes with or without free DMSO molecules and for commercial E-88.

The hexanuclear complex with free DMSOs means the hexanuclear Al-complex in the absence of eight free DMSOs (see Table I) is quite stable, up to $270^{\circ} \mathrm{C}$. Then, the decomposition starts abruptly in a narrow temperature range. On the other hand, the hexanuclear Al-complex as recrystallized exhibits a weight loss of about $15.74 \%$ in the temperature range between 30 and $165^{\circ} \mathrm{C}$ that corresponds approximately to six free DMSO molecules. (Two free DMSOs are missing in the present recrystallized sample as compared with the composition of the single crystal. The recrystallized samples, which were allowed to stand at room temperature often contained a smaller number of free DMSOs.) The present result indicates that the hexanuclear complex in complete absence of free DMSO appears at about $165^{\circ} \mathrm{C}$. The bare hexanuclear complex remains quite stable up to $270^{\circ} \mathrm{C}$, above which the complex starts to decompose.

Commercial E-88, on the other hand, remains stable up to $150^{\circ} \mathrm{C}$. Decomposition starts to occur gradually in a broad temperature range between 130 and $170^{\circ} \mathrm{C}$. This suggests that there are various kinds of Al-complexes with different sizes in commercial E-88. In contrast, the decomposition range in crystals of the hexanuclear complex is narrow and the powders are characterized by a single structure. This result indicates that the hexanuclear complex possesses a much higher thermal stability than commercial E- 88 by about $100^{\circ} \mathrm{C}$.

\section{Characterization of Recryrstallized Powders from Different Solvents}

Growth of single crystals requires a great deal of care in general. However, the polycrystalline powders of the hexanuclear Al-complex can easily be prepared in the following way. For example, $0.5 \mathrm{~g}$ of commercial E- 88 was dis-

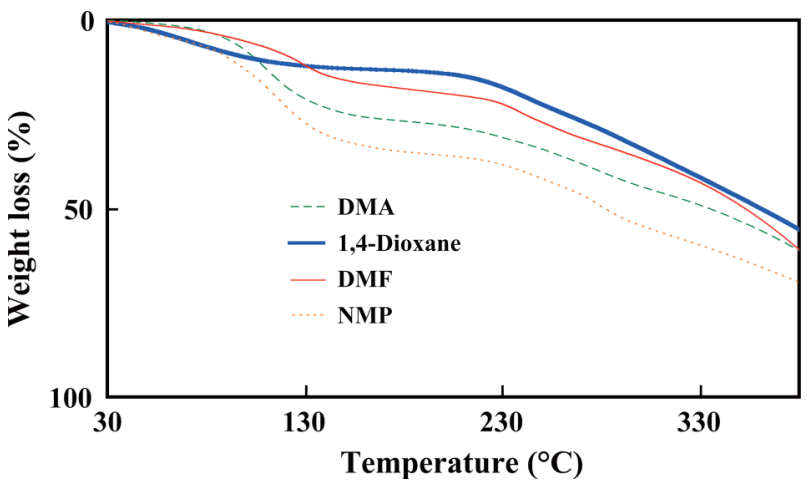

Figure 7. TGA curves for recrystallized E-88 from solution in DMA, DMF NMP, and 1,4-dioxane.

solved in $50 \mathrm{ml}$ of DMSO at about $120^{\circ} \mathrm{C}$ and stirred for several minutes. The E- 88 was completely dissolved and the solution was colorless and transparent. Further stirring at the same temperature for several minutes made the transparent solution white and cloudy. This is a clear indication for the start of the formation of the hexanuclear Al-complex. At this moment, the turbid solution was allowed to stand for cooling to room temperature. The crystalline powders filtered were identified as the same phase as the single crystal of the hexanuclear Al-complex. On the other hand, no formation of the hexanuclear Al-complex was observed when the DMSO solution was cooled down before the appearance of the turbid state. Recrystallization from alcohols, ketones, and ethers gave no turbid state even with continuing stirring.

On the other hand, the solvents that are commonly used for organic pigments (for example, DMA, DMF, NMP, and 1,4-dioxane) gave results as good as that of DMSO solution. In spite of the present intriguing results, the mechanism or driving force of the formation of the hexanuclear Alcomplex remains still unclarified.

Figure 7 shows the TGA curves for the recrystallized samples from solution in DMA, 1,4-dioxane, DMF, and NMP. All the samples are found to include free solvent molecules as shown by the decrease in weight loss in the temperature range between 30 and $120^{\circ} \mathrm{C}$. The second decrease in weight corresponds to the decomposition of the sample. The present results indicate that all the samples in the absence of the free solvent molecules remain stable up to about $230^{\circ} \mathrm{C}$.

Figure 8 shows the characteristic powder $\mathrm{x}$-ray diffraction diagrams, which are typical of samples recrystallized from solution in DMSO, DMA, DMF, NMP, and 1,4-dioxane together with commercial E-88 in the range between $2 \theta=3^{\circ}$ and $9^{\circ}$. All the recrystallized samples were well crystallized (especially from DMSO and DMA) and also showed a number of diffractions in the higher diffraction angles up to $30^{\circ}$. On the other hand, commercial E-88 gave only one broad diffraction band around $2 \theta=4.9$ in the range up to $2 \theta=30^{\circ}$. This indicates the poor crystallinity of commercial E-88. The two diffraction peaks at $2 \theta=5.4^{\circ}$ and $5.9^{\circ}$ of the sample recrystallized from a DMSO solution are assigned to 


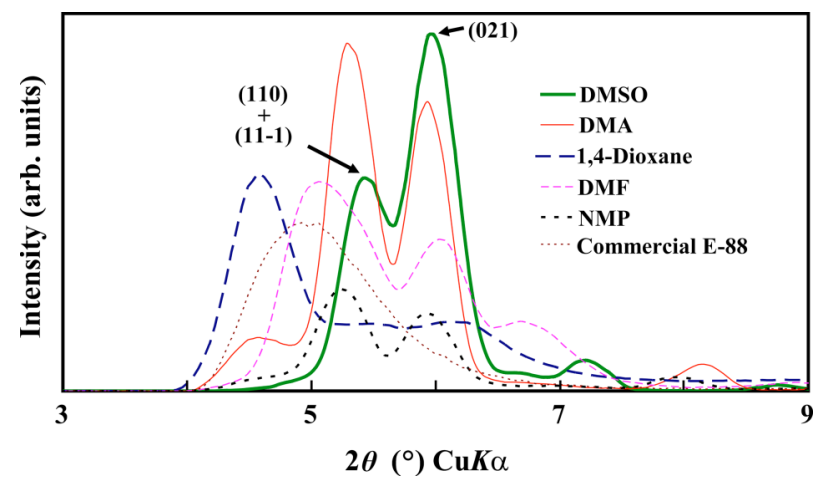

Figure 8. Powder $x$-ray diffraction diagrams for recrystallized E-88 from solution in DMSO, DMA, DMF, NMP, and 1,4-dioxane together with commercial E-88 powders.

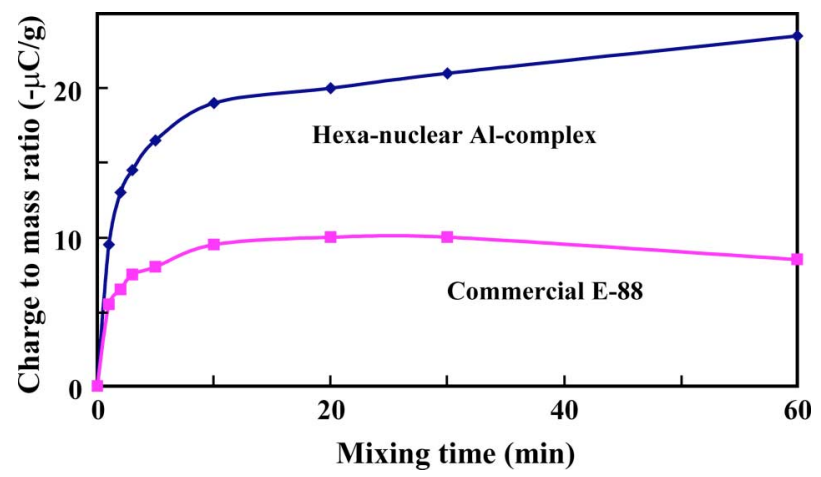

Figure 9. Charging characteristics of toners which include the hexanuclear complex of E-88 or commercial E-88.

the overlapped (110) and (11-1) planes and to the (021) plane, respectively, on the basis of the result obtained from the structure analysis on single crystals. The two similar peaks are also found in samples recrystallized from NMP and DMF solutions. In addition to these two peaks, another characteristic peak also appears around $2 \theta=4.5^{\circ}$ in the DMA and 1,4-dioxane samples. Especially in the dioxane sample, this peak is strong, while the other two bands around $2 \theta=5.4^{\circ}$ and $5.9^{\circ}$ are quite weak. This indicates that the phase of the dioxane sample deviates significantly from that of the other samples.

As judged from the above results, it is highly probable that the hexanuclear or pseudo-hexanuclear complexes are formed in recrystallized samples from DMA, DMF, NMP, and 1,4-dioxane solutions.

As a reference experiment, E- 88 was synthesized using DMSO as the solvent in accordance with the method described in Ref. 5. The product obtained was identified by $\mathrm{XRD}$ as the same phase as that of the single crystal grown from solution in DMSO.

\section{Triboelectrification of Toner Which Includes the Hexanuclear Complex}

Figure 9 shows the charging characteristics of toners which include the hexanuclear complex in the absence of free DMSO molecules and that which includes commercial E-88

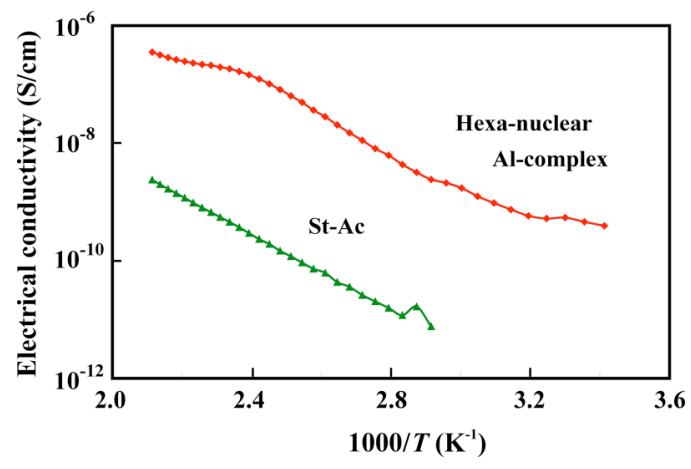

Figure 10. Temperature dependence of the electrical conductivity for the hexanuclear complex.

as a function of time. Toners with the hexanuclear complex also show a rapid charging up to the saturation, and a stable charging level. Thus, the hexanuclear complex also exhibits excellent CCA characteristics. This indicates that the hexanuclear complex, which has a higher thermal stability than that of commercial E-88, can be used as a CCA.

\section{Temperature Dependence of the Electrical Conductivity}

Since E-88 is pictured as an organic semiconductor, the electrical conductivity is expected to follow the Boltzmann distribution function as shown below:

$$
n=n_{0} \exp \left(-\Delta E / k_{B} T\right)
$$

where $n, \Delta E, T$, and $k_{B}$ denote the number of carriers, the activation energy, the temperature, and Boltzmann constant, respectively.

Figure 10 shows the temperature dependence of the electrical conductivity (Arrhenius plot) for the spin-coated deposit of hexanuclear complex and the styrene-acrylic copolymer, which is the main constituent of toners. Good linearity is observed in both samples, indicating the semiconductorlike behavior.

The electrical conductivity of the hexanuclear complex at about $100^{\circ} \mathrm{C}$ is higher than that of room temperature by 1.5 orders of magnitude. Furthermore, the electrical conductivity of St-Ac copolymer is lower than that of the hexanuclear complex by two orders of magnitude in the whole temperature range. This observed temperature dependence of the electrical conductivity of the hexanuclear complex supports our charge-control mechanism described in the Introduction.

\section{CONCLUSIONS}

1. The framework of the hexanuclear complex $(\mathrm{Al} / \mathrm{TBS}=1 / 1.5)$ is composed of two triangles whose apices are occupied by $\mathrm{Al}$ atoms. Each triangle is then formed by bridging two $\mathrm{Al}$ atoms through one tridentate TBS. Furthermore, two triangles form a dimer by connecting two Al-apices by one bidentate TBS, one DMSO, and one hydroxyl anion.

2. The hexanuclear complex shows a higher thermal stability than that of commercial E-88 $(\mathrm{Al} / \mathrm{TBS}=1 / 3)$ by about $100^{\circ} \mathrm{C}$. 
Kamei, Mizuguchi, and Yamate: A highly stable charge-control agent based on an Al-complex with salicylic acid derivatives...

3. The hexanuclear complex also exhibits an excellent CCA characteristic. The hexanuclear complex, which shows a higher thermal stability than that of commercial E-88, can be used as a CCA.

4. The electrical conductivity of the hexanuclear complex at about $100^{\circ} \mathrm{C}$ is higher than that at room temperature by 1.5 orders of magnitude. This supports our charge-control mechanism.

5. Commercial E- 88 is apparently composed of various kinds of Al-complexes with different sizes.

\section{REFERENCES}

${ }^{1}$ J. Mizuguchi, A. Hitachi, Y. Sato, and K. Uta, "Study of the charge control mechanism of charge control agents", J. Imaging Sci. Technol. 52, 030506 (2008).

${ }^{2}$ C. Kittel, Introduction to Solid State Physics, 6th ed. (Wiley, New York, 1986).

${ }^{3}$ G. M. Sherdrick, "SHELXS97", University of Göttingen, Germany (1997).

${ }^{4}$ G. M. Sherdrick, "SHELXL97", University of Göttingen, Germany (1997).

${ }^{5}$ K. Sukata, T. Tsuruhara, S. Yamanaka, S. Sugawara, and M. Yasumatsu, "Metal complexes of aromatic oxycaroboxylic acids and their related compounds", Japan Pending Patent Application Heisei 9-124659 (1996). 
(C)2009 Society for Imaging Science and Technology (IS\&T)

All rights reserved. This paper, or parts thereof, may not be reproduced in any form without the written permission of IS\&T, the sole copyright owner of The Journal of Imaging Science and Technology.

For information on reprints or reproduction contact

Donna Smith

Production Editor

The Journal of Imaging Science and Technology

Society for Imaging Science and Technology

7003 Kilworth Lane

Springfield, Virginia 22151 USA

703/642-9090 extension 107

703/642-9094 (fax)

dsmith@imaging.org

www.imaging.org 